\title{
АЦП и ЦАП Analog Devices: обзор новинок 2018 года
}

B. Ежов

УДК 621.3.049.774 | ВАК 05.27.01

Analog Devices - один из ведущих разработчиков и производителей аналогоцифровых и цифро-аналоговых преобразователей. Компания занимает лидирующие позиции в отрасли, выпускает сотни типов АЦП и ЦАП с различной архитектурой, отличающихся скоростью преобразования, разрядностью, числом каналов и другими параметрами. Изделия производителя ориентированы на широкий спектр приложений: от промышленных контроллеров и базовых станций сотовой связи до прецизионных измерительных приборов и систем сбора данных. Представляя новые разработки в области АЦП и ЦАП, компания Analog Devices учитывает разнообразные требования заказчиков и предлагает оптимальные решения для конкретного приложения. Рассмотрим новинки, представленные компанией в прошлом году, их особенности, ключевые параметры, перспективные области применения в России.

\section{АНАЛОГО-ЦИФРОВЫЕ ПРЕОБРАЗОВАТЕЛИ}

Вся номенклатура АЦП, выпускаемых Analog Devices, традиционно подразделяется на два класса: быстродействующие и прецизионные. К быстродействующим компания относит приборы с частотой выборки более 10 Мвыб./с, однако освоение СвЧ-диапазона и необходимость обработки субнаносекундных импульсных сигналов требует достижения скорости преобразования более 1 Гвыб. / с. Поэтому в данную категорию изделий от Analog Devices входит широкий спектр приборов со скоростью от 10 Мвыб. / с до 3 Гвыб. / с, разрядностью от 8 до 18 и числом каналов от 1 до 8. Для построения быстродействующих АЦП используется, главным образом, конвейерная архитектура, хотя в этом классе преобразователей Analog Devices встречаются также АЦП последовательного приближения и даже сигма-дельта АЦП.

Среди новинок Analog Devices в категории быстродействующих АЦП следует отметить два прибора - AD9697 и LTM2173-14 (табл. 1).

AD9697-одноканальный 14-разрядный АЦП с частотой выборки 1,3 Гвыб. / с, оснащенный встроенным буфером и схемой выборки-хранения на дифференциальном входе (рис. 1). Прибор отличается низким потреблением (1,01 ВТ на частоте 1,3 ГГц) и простотой применения. Входная полоса частот АЦП по уровню -3 дБ составляет 2 ГГц.

Данный АЦП предназначен для применения в программно-определяемых радиосистемах, коммуникационных системах для прямой выборки широкополосного аналогового сигнала, быстродействующих осциллографах, анализаторах спектра и высокоскоростных системах сбора данных. Кроме того, возможными областями применения AD9697 могут быть высокоскоростные осциллографы, анализаторы спектра и векторные анализаторы сетей

AD9697 построен на базе многокаскадной дифференциальной конвейерной архитектуры со встроенной

Таблица 1. Быстродействующие АЦП

\begin{tabular}{|c|c|c|}
\hline Модель & AD9697 & LTM2173-14 \\
\hline Количество каналов & 1 & 4 \\
\hline Разрешение, бит & 14 & 14 \\
\hline $\begin{array}{l}\text { Частота выборки, } \\
\text { Мвыб./с (макс.) }\end{array}$ & 1300 & 80 \\
\hline Архитектура & Конвейерн. & - \\
\hline $\begin{array}{l}\text { Отношение сигнал / шум, } \\
\text { дБ Пш (тип.) }\end{array}$ & 65,6 & 73 \\
\hline $\begin{array}{l}\text { Интегр. нелинейность, } \\
\text { МЗР (тип.) }\end{array}$ & 1 & 1 \\
\hline $\begin{array}{l}\text { Вход. напряжение, } \\
\text { Вп-п (тип.) }\end{array}$ & 1,59 & 2 \\
\hline $\begin{array}{l}\text { Потребл. мощность, } \\
\text { Вт (тип.) }\end{array}$ & 1,01 & 0,385 \\
\hline Выход. интерфейс & JESD204B & Послед. LVDS \\
\hline
\end{tabular}




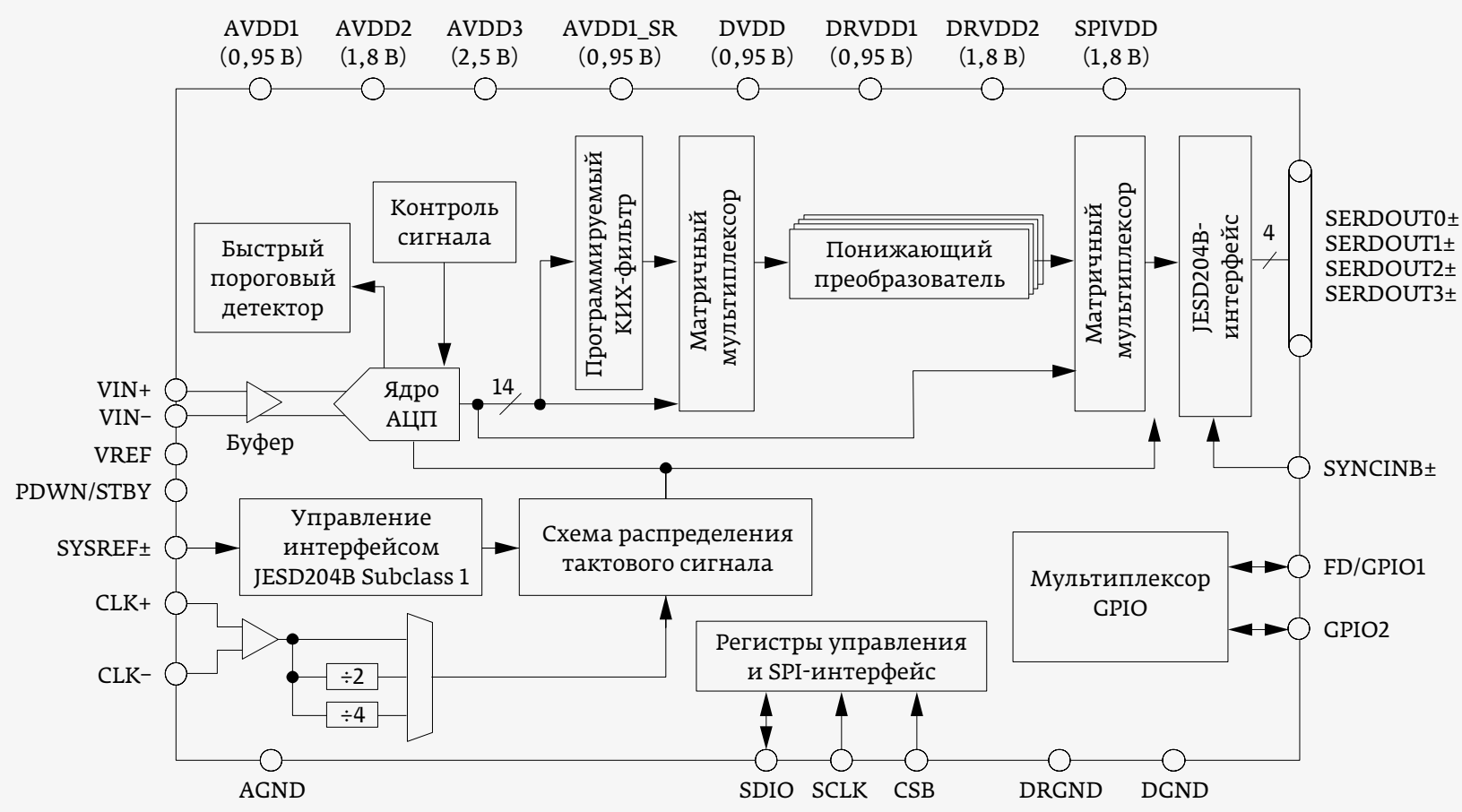

\section{Рис. 1. Блок-схема АЦП AD9697}

логикой коррекции ошибок на выходе. Возможен выбор пользователем входного диапазона напряжений от 1,36 до 2,04 Вп-п (типовой диапазон - 1,59 Вп-п). Встроенный источник опорного напряжения упрощает проектирование системы на базе этого АЦП.

Выходы данных АЦП подключены с помощью матричного мультиплексора к четырем цифровым преобразователям с понижением частоты (передискретизаторам), каждый из которых содержит несколько каскадов обработки сигнала в составе 48-разрядного конвертора частоты (генератор с цифровым управлением) и фильтров децимации. В генераторе с цифровым управлением предусмотрена опция выбора до 16 предустановленных частотных диапазонов для выводов общего назначения. Управление режимами работы блоков цифровых преобразователей частоты осуществляется через SPI-интерфейс.

Кроме того, в AD9697 реализовано несколько функций, упрощающих автоматическую регулировку усиления в коммуникационных приемниках. Быстрый программируемый пороговый детектор обеспечивает контроль мощности входного сигнала, чтобы предотвратить выход амплитуды сигнала за пределы входного диапазона АЦП. Специальный блок контроля уровня сигнала дает дополнительную информацию о входном сигнале.

у пользователя есть возможность сконфигурировать последовательный выход (интерфейс
JESD204B Subclass 1) в одну, две или четыре линии в зависимости от конфигурации передискретизаторов и допустимой скорости приемной логики. Возможна синхронизация нескольких АЦП, для чего предусмотрены специальные выводы SYSREF \pm и SYNCINB \pm .

B AD9697 реализованы также опции пониженного энергопотребления, программируемые через 3-проводный SPI-интерфейс и специальный вывод PDWN / STBY. Устройство доступно в 64-выводном корпусе LFCSP, диапазон рабочих температур АЦП - от -40 до $105^{\circ} \mathrm{C}$.

Еще одна новинка в линейке быстродействующих АЦП Analog Devices - LTM2173-14 (рис. 2). Это 4-канальный 14-разрядный АЦП с одновременной выборкой. Отношение сигнал / шум устройства составляет 73 дБ полной шкалы, динамический диапазон без паразитных составляющих - 88 дБ, частота выборки - 80 Мвыб. / с.

LTM2173-14 отличается низким потреблением (всего 96 мВт на канал), питание осуществляется от одного источника напряжения 1,8 В. Встроенный в ИС развязывающий конденсатор и цоколевка выводов типа flowthrough упрощает разводку печатной платы и уменьшает занимаемое на плате место.

АЦП оснащены последовательным LVDS-выходом, каждый выходной канал может работать в режиме одной или двух линий (считывается одновременно 1 или 2 бита на канал). Для конфигурирования устройства используется последовательный SPI-интерфейс. 


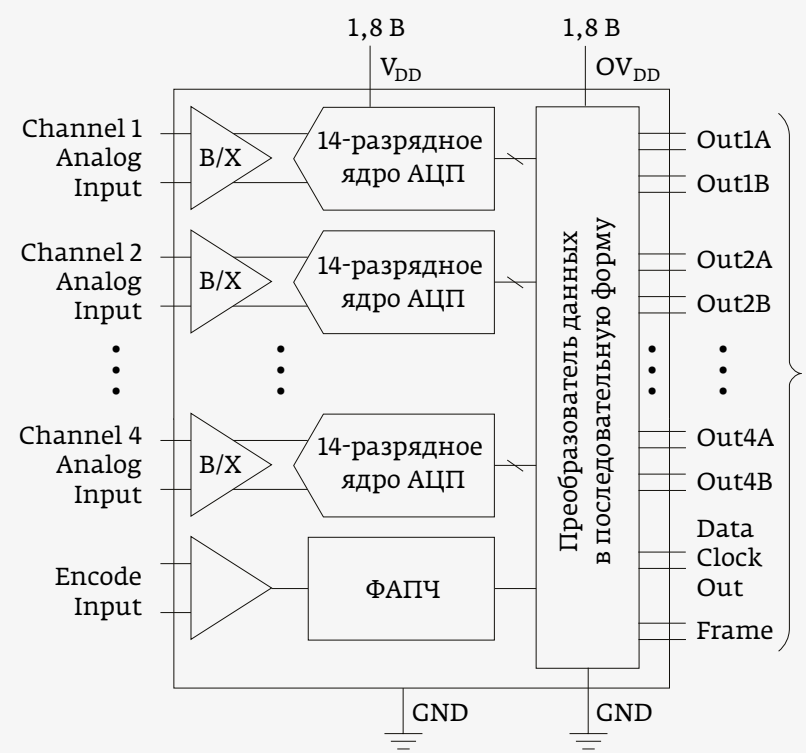

В/X - схема выборки/хранения

\section{Рис. 2. Блок-схема АЦП LTM2173-14}

Пользователь может выбирать входной диапазон напряжений от 1 до 2 Вп-п. Встроенный стабилизатор рабочего цикла тактового сигнала обеспечивает высококачественный тактовый сигнал на максимальной частоте.

LTM2173-14 предлагается в 140-выводном корпусе BGA и работает в диапазоне температур от -40 до $105^{\circ} \mathrm{C}$.

Основные области применения этого АЦП: автомобильная электроника, коммуникационные системы, базовые станции сотовой связи, портативные диагностические приборы визуализации, неразрушающий контроль, многоканальные системы сбора данных.

Еще одна категория АЦП, выпускаемых компанией Analog Devices, - прецизионные АЦП с частотой выборки менее 10 Мвыб. / с. Этот класс АЦП - ключевой компонент любой системы сбора и обработки сигналов, поскольку именно он определяет характеристики системы. В линейке прецизионных АЦП от Analog Devices - устройства с разрешением от 8 до 32 бит, для их реализации применяют, как правило, две архитектуры - на основе регистра последовательного приближения (SAR) и сигма-дельта. Разработчику прецизионных схем сбора данных необходимо выбирать АЦП исходя из баланса таких параметров, как уровень шума, ширина полосы и время установления. Всю номенклатуру прецизионных АЦП от Analog Devices можно разделить на три подкатегории: многоканальные АЦП, АЦП с одновременной выборкой и одноканальные АЦП.

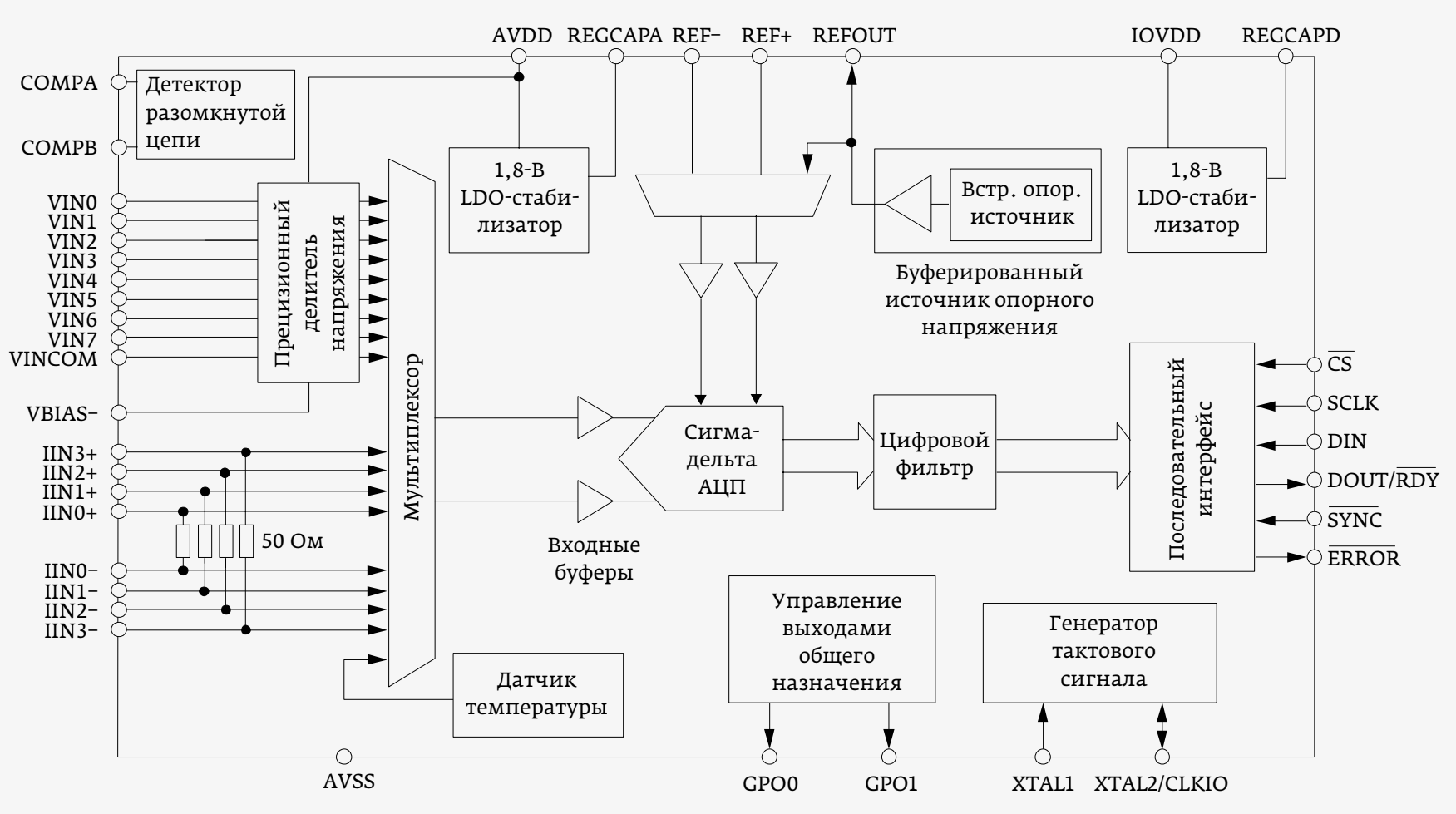

Рис. 3. Блок-схема АЦП AD4111 
Новинка 2018 года среди прецизионных АЦП с мультиплексированием каналов - AD4111 / AD4112 - 24-разрядный сигма-дельта АЦП с низким уровнем шума и малым потреблением (рис. 3). Устройство оснащено мультиплексированным аналоговым интерфейсом с четырьмя полностью дифференциальными или восемью несимметричными входами с высоким входным сопротивлением (более 10 МОм). Кроме входов по напряжению (входной диапазон \pm 10 В) АЦП содержит также токовые входы (от 0 до $20 \mathrm{MA}$ ).

B AD4111/AD4112 предусмотрена возможность конфигурирования каждого аналогового входного канала, используемого в системе (до восьми предустановок). Максимальная скорость сканирования каналов достигает 6,2 квыб. / с. Встроенный в АЦП источник опорного напряжения 2,5 В на ширине запрещенной зоны с низким дрейфом (5 ppm $\left./{ }^{\circ} \mathrm{C}\right)$ позволяет уменьшить количество компонентов в системе.

Цифровой фильтр предусматривает гибкие установки, в том числе одновременное подавление шума на частотах 50 и 60 Гц. Пользователь может выбрать установки цифрового фильтра в зависимости от требования конкретного приложения. Автоматический контроллер последовательности позволяет АЦП переключаться между каждым задействованным каналом.

Прецизионные характеристики AD4111/AD4112 достигаются благодаря применению патентованной технологии iPassives. Калибровка АЦП в условиях производства позволяет достичь высокого уровня требуемой точности.

Отличие AD4111 от AD4112 состоит в том, что AD4111 снабжен уникальной функцией детектирования разомкнутой цепи на входах, что позволяет реализовать диагностику системы, используя один источник питания (5 или 3,3 B).

АЦП AD4111 / AD4112 поставляются в компактных 40-выводных корпусах LFCSP с габаритами 6×6 мм. Диапазон рабочих температур - от -40 до $105^{\circ} \mathrm{C}$.

Устройства предназначены главным образом для применения в системах промышленной автоматизации (в программируемых логических контроллерах и распределенных системах управления).

Новинки Analog Devices в категории прецизионных одноканальных АЦП - это AD7768-1 и AD4002 (табл. 2).

AD7768-1 - высококачественный одноканальный 24-разрядный сигма-дельта АЦП со встроенным цифровым фильтром, сочетающий высокие динамические и статические характеристики с низким потреблением (рис. 4). Динамический диапазон этого АЦП достигает 108,5 дБ при использовании цифрового КИХ-фильтра на частоте выборки 256 квыб. / с и обеспечивает входную полосу частот 110,8 кГц. Ошибка смещения не превышает \pm 30 мкВ, отклонение коэффициента усиления - \pm 30 ppm. Более
Таблица 2. Одноканальные прецизионные АЦП

\begin{tabular}{|c|c|c|}
\hline Модель & AD7768-1 & AD4002 \\
\hline Количество каналов & 1 & 1 \\
\hline Разрешение, бит & 24 & 18 \\
\hline $\begin{array}{l}\text { Частота выборки, } \\
\text { Мвыб./с (макс.) }\end{array}$ & 1,024 & 2 \\
\hline Архитектура & $\begin{array}{l}\text { Сигма- } \\
\text { дельта }\end{array}$ & $\begin{array}{c}\text { Регистр } \\
\text { послед. } \\
\text { приближе- } \\
\text { ния }\end{array}$ \\
\hline $\begin{array}{l}\text { Интегр. нелинейность, } \\
\text { МзР (тип.) }\end{array}$ & - & 0,8 \\
\hline $\begin{array}{l}\text { Отношение сигнал / шум, } \\
\text { дБ Пш (тип.) }\end{array}$ & 108 & 95 \\
\hline $\begin{array}{l}\text { Потребл. мощность, мВт } \\
\text { (тип.) }\end{array}$ & 26,4 & 14 \\
\hline $\begin{array}{l}\text { Выход. } \\
\text { интерфейс }\end{array}$ & SPI & $\begin{array}{l}\text { Послед., } \\
\text { SPI }\end{array}$ \\
\hline Тип входа & $\begin{array}{l}\text { Дифферен- } \\
\text { циальный }\end{array}$ & $\begin{array}{c}\text { Псевдо- } \\
\text { дифферен- } \\
\text { циальный }\end{array}$ \\
\hline
\end{tabular}

широкая полоса (до 500 кГц) доступна при использовании sinc5-фильтра.

AD7768-1 позволяет динамически анализировать меняющийся входной сигнал, что делает это устройство незаменимым для построения высококачественных систем сбора данных. Предусмотренные в AD7768-1 три режима работы (быстрый, средний и режим низкого энергопотребления) дают возможность пользователю выбрать оптимальное соотношение между входной полосой, скоростью выходных данных и потребляемой мощностью. Выбор одного из трех режимов энергопотребления позволяет разработчику системы достичь требуемых показателей уровня шума при минимальном потреблении.

B AD7768-1 реализованы расширенные возможности цифровой фильтрации сигнала, отвечающие широкому спектру системных требований, в том числе:

- КИХ-фильтр с малым уровнем пульсаций (неравномерность в полосе пропускания $\pm 0,005$ дБ на частоте 102,4 кГц);

- $\operatorname{sinc5-фильтр~с~малой~задержкой~и~скоростью~пере-~}$ дачи данных до 1,024 МГц;

- полностью программируемый sinc3-фильтр с малой задержкой и возможностью подавления сигнала 50/60 Гц. 


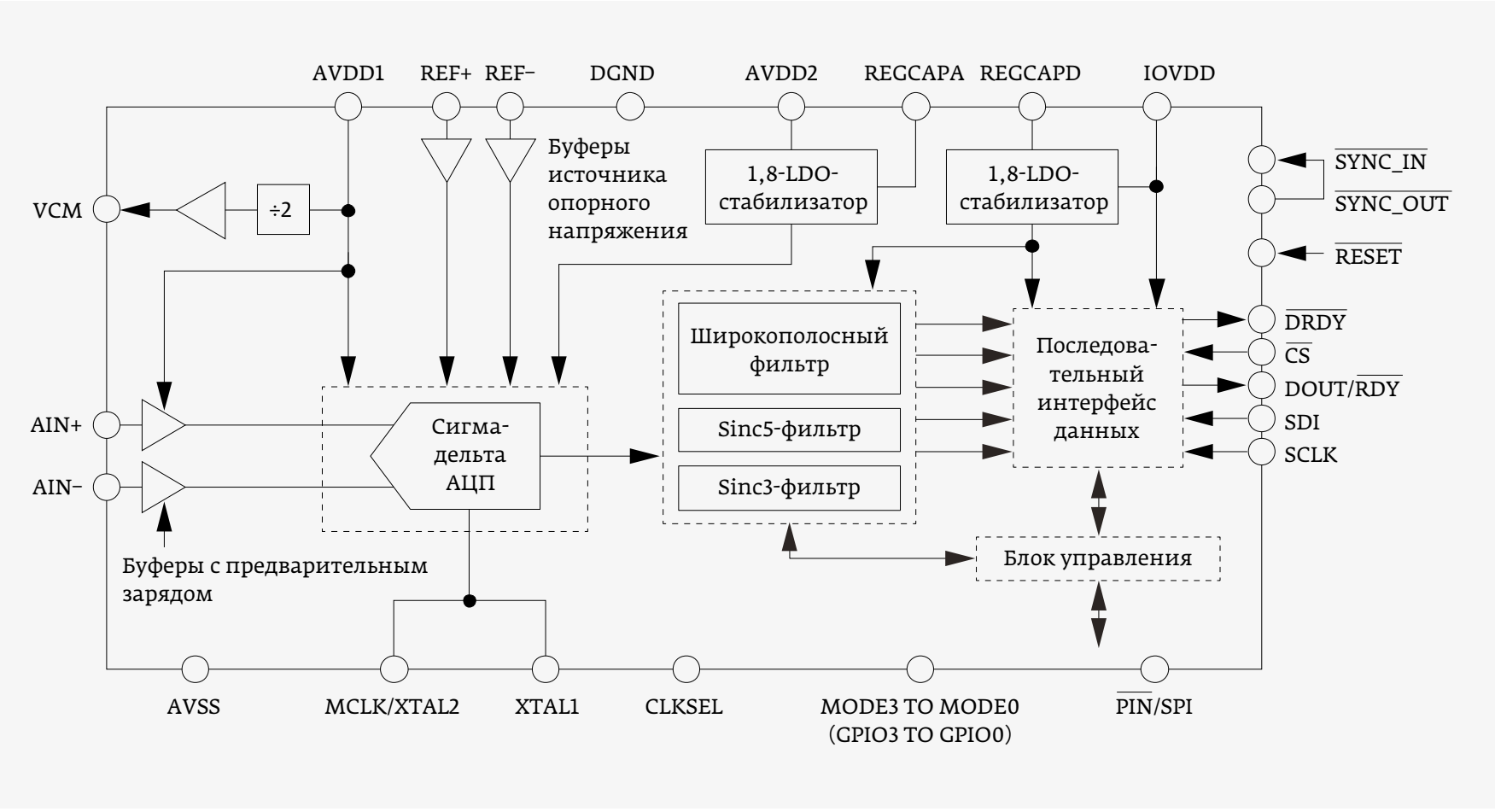

\section{Рис. 4. Блок-схема АЦП AD7768-1}

AD7768-1 содержит буфер с предварительным зарядом на аналоговом входе, который снижает входной ток, что упрощает выбор внешнего усилителя. Буферированный вход источника опорного напряжения обеспечивает снижение входного тока и высокоомный вход для внешнего опорного источника. Устройство работает с внешним источником опорного напряжения в диапазоне от 1 В до питающего напряжения AVDDI (5 B). Кроме 5-В источника для питания АЦП нужны еще два источника - от 2 до 5 В (AVDD2) и от 1,8 до 3,3 В (IOVDD). В режиме низкого потребления все три источника могут питаться от одной 3,3-В шины.

Устройство поставляется в компактном 28-выводном корпусе LFCSP ( 4 ×5 мм), рабочий диапазон температур От -40 до $125^{\circ} \mathrm{C}$.

Ключевые области применения AD7768-1: высокоточные измерительные системы, мониторинг параметров в диагностических системах, контроль показателей жизненно важных функций в клиническом медицинском оборудовании, модульные системы сбора данных с изолированными каналами и др.

Еще одна новинка в категории одноканальных прецизионных АЦП - AD4002 - быстродействующий 18-разрядный АЦП последовательного приближения с пропускной способностью 2 Мвыб./с (рис. 5). Ряд функций устройства позволяет уменьшить энергопотребление сигнальной цепи, понизить ее сложность и повысить плотность каналов в системе.
Высокоимпедансный режим AD4002 совместно с длительной фазой захвата дает возможность отказаться от специального быстродействующего драйвера АЦП, чтобы использовать в качестве интерфейса широкий набор усилителей, обеспечивая оптимальный уровень характеристик. Функция компрессии входного диапазона позволяет AD4002 и усилителю-драйверу работать от общего напряжения питания без необходимости применять отрицательное напряжение, не уменьшая диапазон преобразования АЦП. Низкая частота последовательного интерфейса SPI уменьшает мощность, потребляемую цепями цифрового ввода-вывода, расширяет спектр совместимых процессоров и упрощает задачу передачи данных через изоляционный барьер.

AD4002 работает от источника напряжения 1,8 B и осуществляет выборку аналогового входного сигнала (IN+) в диапазоне от O B до $V_{\text {REF }}$ по отношению к напряжению земли (IN-). Опорное напряжение $\mathrm{V}_{\mathrm{REF}}$ Может изменяться в диапазоне от 2,4 до 5,1 В. АЦП потребляет всего 14 мВт при частоте выборки 2 Мвыб./с, обеспечивает разрядность 18 бит без пропуска кодов и отношение сигнал / шум на уровне 95 дБ. Устройство работает с внешним опорным напряжением, которое может устанавливаться независимо от напряжения питания.

SPI-совместимый универсальный последовательный интерфейс предусматривает семь различных рабочих режимов, включая возможность объединения нескольких АЦП в цепочку с последовательным опросом на одной 


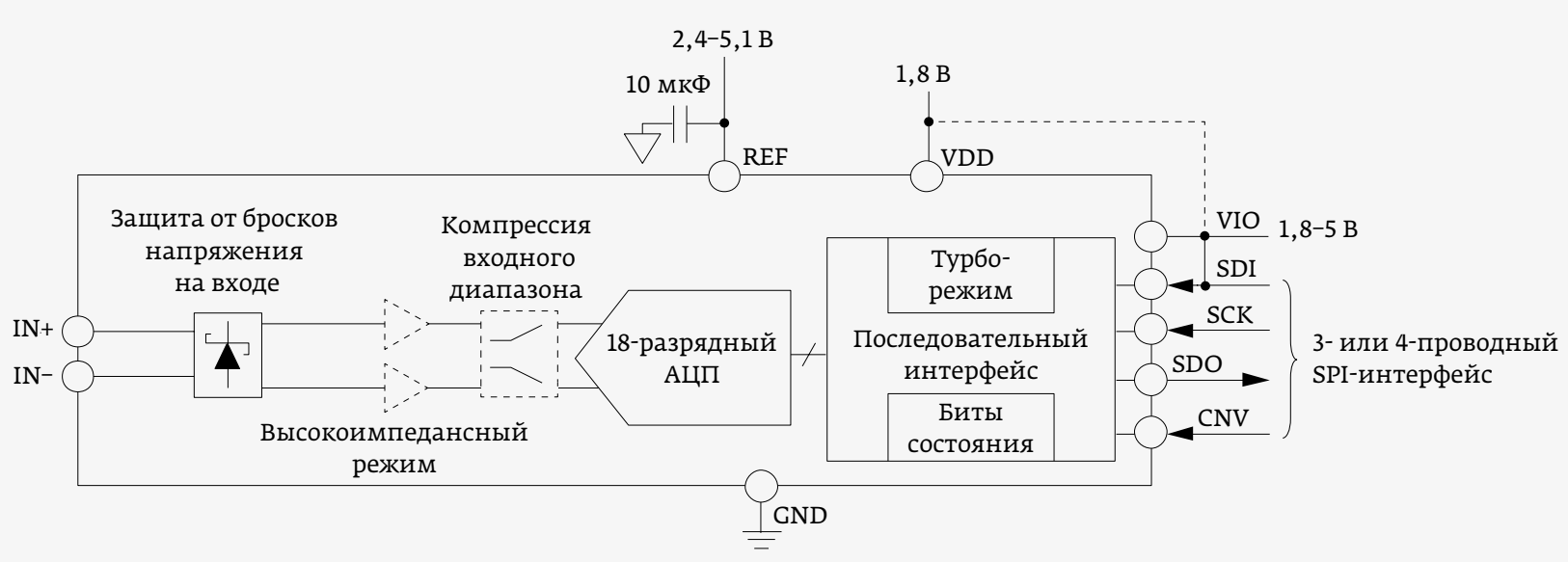

Рис. 5. Блок-схема АЦП AD4002

трехпроводной шине. Благодаря отдельному напряжению питания VIO AD4002 поддерживает совместимость с логическими схемами с напряжением питания 1,8; 2,5; 3 и 5 B.

AD4002 выпускается в 10-выводных корпусах MSOP и LFCSP, рабочий температурный диапазон составляет от -40 до $125^{\circ} \mathrm{C}$

Перспективные области применения AD4002: автоматизированное тестовое оборудование, автоматизация механизмов, медицинское оборудование, оборудование с питанием от батарей, прецизионные системы сбора данных.

В категории АЦП с одновременной выборкой компания Analog Devices за прошедший год также представила новинки - LTC2353-16 и LTC2357-18 (табл. 3). Прецизионные АЦП с одновременной выборкой позволяют преобразовывать несколько сигналов одновременно, сохраняя информацию о фазе. Эти АЦП востребованы в таких областях, как системы автоматизации распределительной сети, ультразвуковые измерения, управление двигателями.

LTC2353-16 - 2-канальный 16-разрядный АЦП последовательного приближения с одновременной выборкой и буферированным входом (рис. 6). Устройство работает от одного источника питания с напряжением 5 В, содержит встроенный источник опорного напряжения и буфер. Оба канала можно независимо друг от друга конфигурировать и устанавливать на входах различные диапазоны напряжения: $\pm 10,24$ B, от 0 до 10,24 B, $\pm 5,12$ В или от 0 до 5,12 В. Один канал можно отключать, чтобы повысить пропускную способность другого канала.

Максимальная утечка на входе аналогового буфера не превышает 500 пА при температуре $85^{\circ} \mathrm{C}$. Коэффициент ослабления синфазного сигнала на входной частоте 200 Гц составляет 124 дБ, а отношение сигнал / шум 94,2 дБ полной шкалы. Эти характеристики позволяют упростить применение АЦП для оцифровки высоковольтных сигналов с широким динамическим диапазоном.

LTC2353-16 поддерживает на выходе последовательный КМOП SPI-интерфейс (1,8-5 В) или последовательный LVDS-интерфейс. Чтобы пользователь мог оптимизировать ширину и пропускную способность шины данных,

Таблица 3. АЦП с одновременной выборкой

\begin{tabular}{lcc} 
Модель & LTC2353-16 & LTC2357-18 \\
$\begin{array}{l}\text { Количество } \\
\text { каналов }\end{array}$ & 2 & 4 \\
\hline
\end{tabular}

\begin{tabular}{lcc}
\hline Разрешение, бит & 16 & 18 \\
\hline $\begin{array}{l}\text { Частота выборки, } \\
\text { квыб./с (макс.) }\end{array}$ & 550 & 350 \\
\hline
\end{tabular}

\begin{tabular}{lcc}
\hline Архитектура & Регистр & Регистр \\
& послед. & послед. \\
& приближения & приближения
\end{tabular}

$\begin{array}{lll}\text { Интегр. нелиней- } & 0,3 & 1 \\ \text { ность, МЗР (тип.) } & & \end{array}$

\begin{tabular}{lcc}
\hline $\begin{array}{l}\text { Отношение } \\
\text { сигнал/шум, }\end{array}$ & 94,2 & 96,4 \\
дБ Пш (тип.) & & \\
\hline $\begin{array}{l}\text { Потребл. мощность, } \\
\text { мВт (тип.) }\end{array}$ & 162 & 174 \\
\hline
\end{tabular}

\begin{tabular}{lcc}
\hline Выход. интерфейс & $\begin{array}{c}\text { Послед. LVDS, } \\
\text { послед. SPI }\end{array}$ & $\begin{array}{c}\text { Послед. LVDS, } \\
\text { послед. SPI }\end{array}$ \\
\hline Тип входа & Дифференц., & Дифференц., \\
& несимм. & несимм. \\
\hline
\end{tabular}




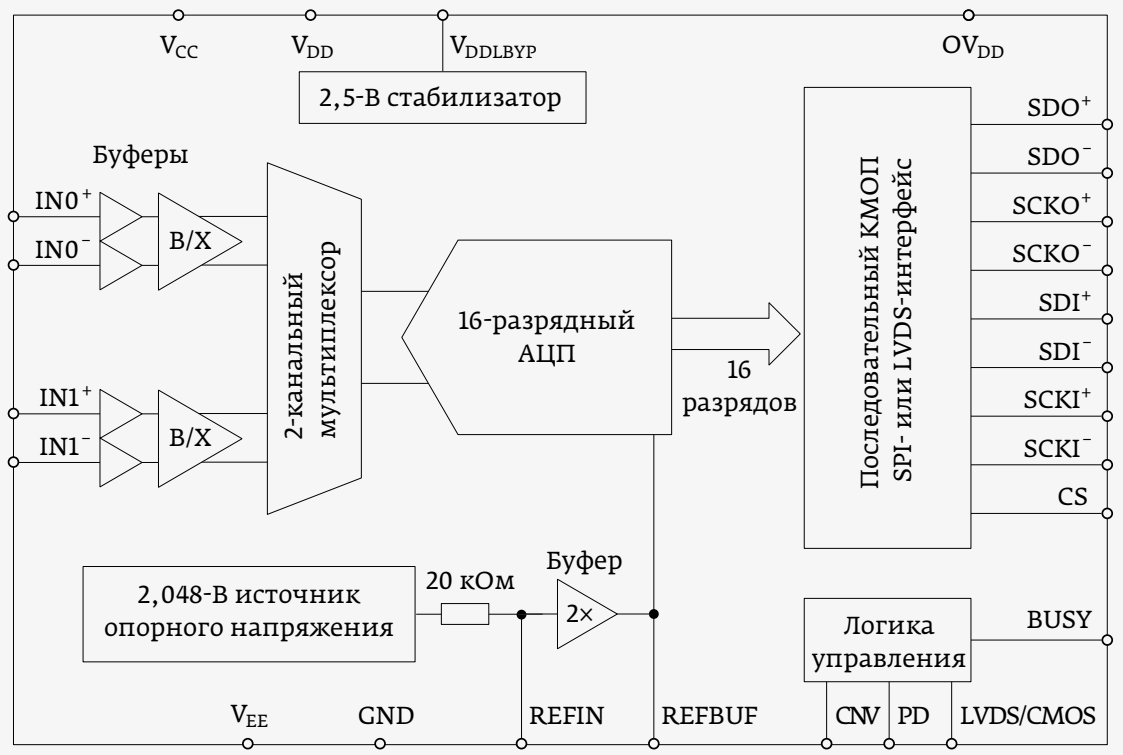

B/X - схема выборки-хранения логических контроллерах, системах промышленного управления, прецизионных измерительных системах, поставляется в 48-выводном корпуce LQFP $(7 \times 7$ мм ) и работает в диапазоне температур от -40 до $125^{\circ} \mathrm{C}$.

\section{ЦИФРО-АНАЛОГОВЫЕ ПРЕОБРАЗОВАТЕЛИ}

Analog Devices предлагает крупнейший в отрасли ассортимент цифроаналоговых преобразователей с разрядностью от 6 до 20 бит. Линейка этого вида продукции включает ЦАП с токовым выходом и выходом по напряжению, интегрированными выходными усилителями, цифровые потенциометры и ЦАП со специальными функциями. Быстродействующие ЦАП (скорость преобразования от 30 Мвыб. / с до 12,6 Гвыб. / с) включают в себя широкополосные ЦАП диапазона ВЧ, ЦАП с цифровой обработкой сигнала ПЧ и универсальные ЦАП диапазона модулирующих частот. Изделия находят применение в системах проводной и беспроводной связи, измерительной технике, радиолокационных системах, системах радиоэлектронного противодействия и др.

Среди новинок Analog Devices в категории быстродействующих ЦАП следует отметить три устройства: AD9176, AD9174 и AD9171 (табл. 4). Эти изделия расширяют новое в АЦП предусмотрена возможность использования одной или двух линий выходных данных в КМОП-режиме.

АЦП LTC2353-16, поставляемый в 48-выводном корпусе LQFP $(7 \times 7$ мм), работает в диапазоне температур от -40 до $125^{\circ} \mathrm{C}$.

Еще одна новинка - LTC2357-18 - 4-канальный 18-разрядный АЦП последовательного приближения с одновременной выборкой и буферированным входом. Это устройство по организации и большей части параметров аналогично 2-канальномy 16-разрядному АЦП LTC2353-16 (см. рис. 6), однако обеспечивает 18-битную разрядность без пропуска кодов. Возможность установки различных диапазонов входного напряжения ( $\pm 10,24$ В, от 0 до 10,24 В, $\pm 5,12$ В или от 0 до 5,12 В), пикоамперная утечка входных буферов, ослабление синфазного сигнала на уровне 128 дБ и типовое значение отношения сигнал/шум на уровне 96,4 дь делают этот АЦП оптимальным вариантом для оцифровки высоковольтных сигналов с широким динамическим диапазоном.

Так же, как и LTC2353-16, АЦП LTC2357-18 применяется В промышленных программируемых
Таблица 4. Быстродействующие ЦАП

\begin{tabular}{lccc} 
Модель & AD9176 & AD9174 & AD9171 \\
Количество каналов & 2 & 2 & 2 \\
\hline Разрешение, бит & 16 & 16 & 16 \\
\hline Частота обновления, Гвыб./с & 12,6 & 12,6 & 6 \\
\hline $\begin{array}{l}\text { Спектральная плотность шума, } \\
\text { дБм/Гц (тип.) }\end{array}$ & 165 & 165 & 165 \\
\hline $\begin{array}{l}\text { SFDR*, дБ (тип.) } \\
\text { Выходной ток полной шкалы, }\end{array}$ & 72 & 72 & 72 \\
$\begin{array}{l}\text { мА (макс.) } \\
\text { Интерфейс входных данных }\end{array}$ & 26 & 26 & 26 \\
& JESB204B, & JESB204B, & JESB204B, \\
\hline Мощность, Вт (тип.) & SPI & SPI & SPI \\
\hline
\end{tabular}

* SFDR - динамический диапазон без паразитных составляющих. 
семейство высокоскоростных ЦАП, созданное на основе недавно освоенного компанией техпроцесса 28 нм.

AD9176/AD9174 (рис. 7) - высокопроизводительные 2-канальные 16-разрядные ЦАП с быстродействием 12,6 Гвыб./с, которые обеспечивают прямой синтез Вч-сигналов с частотой до 6,16 ГГц, исключая необходимость в гетеродине и повышающем преобразовании промежуточной частоты. Это упрощает сквозную цепь прохождения ВЧ-сигнала и снижает общую стоимость системы.

AD9176/AD9174 оснащены универсальным JESD204Bинтерфейсом входных данных на восемь линий с пропускной способностью 15,4 Гвыб. / с, блоками цифровой обработки сигнала и встроенной малошумящей схемой умножителя частоты тактового генератора на основе ФАПЧ.

Устройство имеет по три канала комплексной обработки входных данных на один канал радиочастотного ЦАП. Каждый входной канал, который можно отключать, содержит конфигурируемый усилительный каскад, интерполяционный фильтр и канальный генератор с цифровым управлением, что обеспечивает гибкость многодиапазонного частотного планирования.

Каждая группа по три канала объединяется в основной канал данных для дополнительной обработки сигнала, если в этом возникает необходимость. Каждый основной канал снабжен опциональной защитой усилителя мощности на выходе ЦАП, интерполяционным фильтром и оконечным 48-разрядным программируемым генератором на входе ядра ЦАП. Используя ключ модулятора, выход основного канала данных можно сконфигурировать на один канал ЦАП для работы в режиме одиночного ЦАП либо на два канала ЦАП для работы в режиме сдвоенного ЦАП промежуточной частоты.

AD9176/AD9174 также поддерживают различные режимы скоростей передачи данных, которые позволяют отключать объединитель каналов и основной канал данных для достижения максимальной скорости

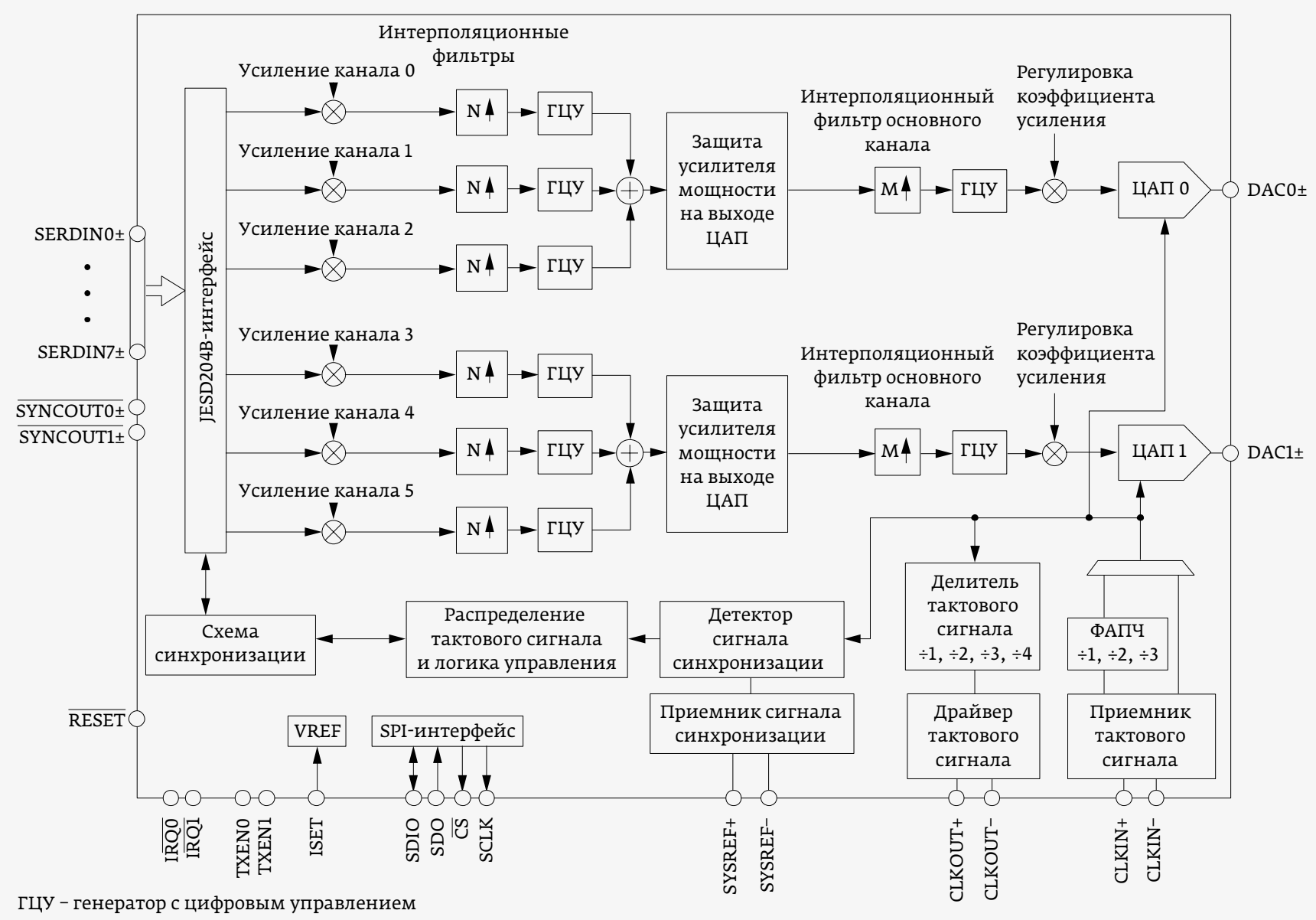

Рис. 7. Блок-схема ЦАП AD9176 


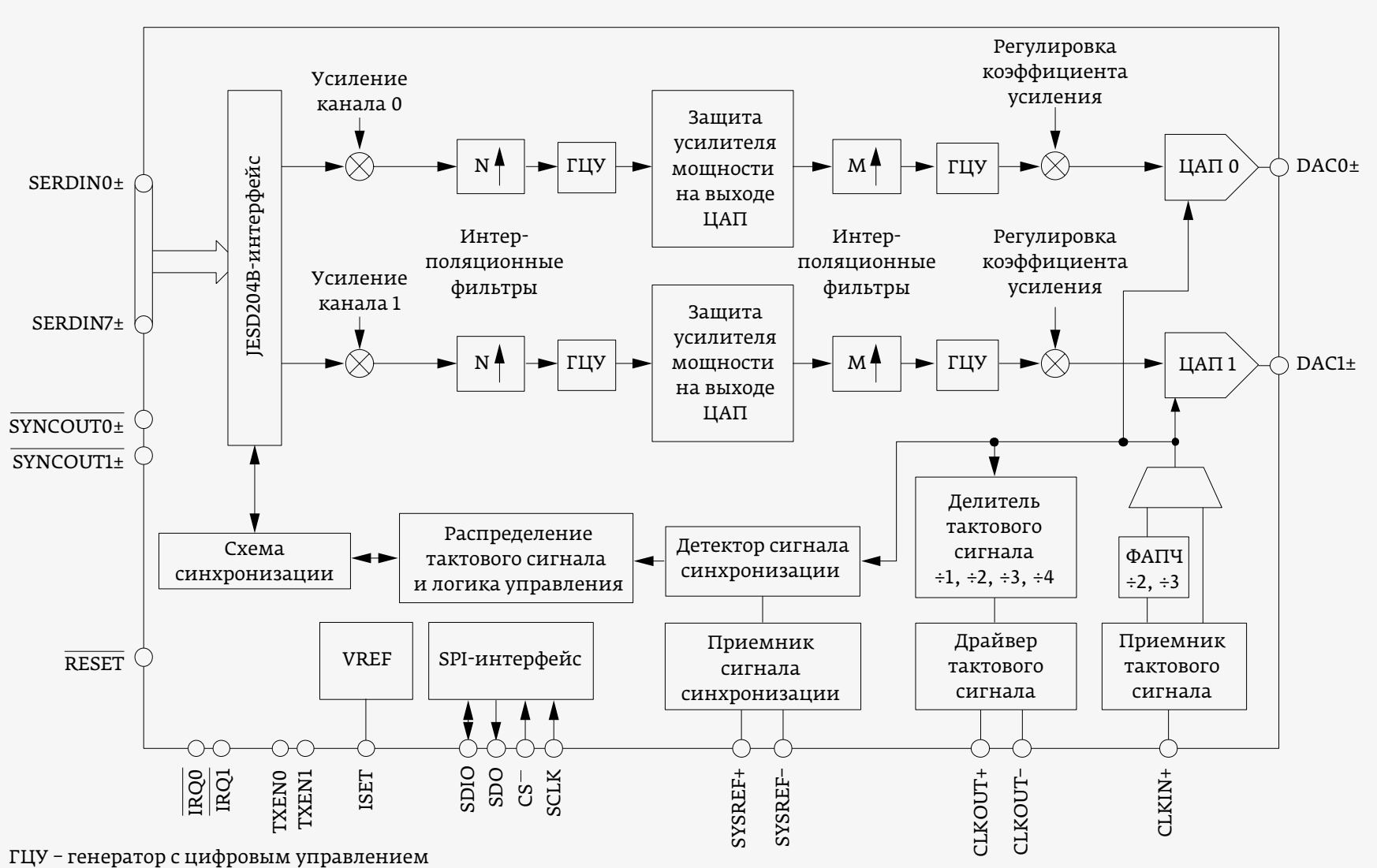

\section{Рис. 8. Блок-схема ЦАП AD9171}

до 6,16 Гвыб. / с в режиме одиночного 16-разрядного ЦАП, до 3,08 Гвыб. / с в режиме сдвоенного 16-разрядного ЦАП или до 4,1 Гвыб./с в режиме сдвоенного 12-разрядноГО ЦАП.

Основные области применения AD9176 / AD9174: инфраструктура беспроводных коммуникаций, многодиапазонные базовые станции связи поколения 4С / 5G, контрольно-измерительные системы, автоматизированное тестовое оборудование, радары и станции радиопомех.

Еще один новый представитель высокоскоростных ЦАП этого семейства - AD917l (рис. 8). Высокопроизводительный 2-канальный 16-разрядный ЦАП поддерживает работу с частотой обновления до 6,2 Гвыб. / с. Как и старшие представители семейства, устройство содержит входной порт JESD204B с восемью линиями данных и пропускной способностью 15,4 Гбит / с, интегрированный высококачественный умножитель тактовой частоты и блоки цифровой обработки сигнала.

В отличие от AD9176 / AD9174, AD9171 оснащен одним комплексным каналом входных данных на каждый из двух каналов радиочастотного ЦАП. Канал входных данных вКлючает в себя конфигурируемый каскад усиления, интерполирующий фильтр и генератор с цифровым управлением.
Устройство поддерживает работу с частотой цифровых сигналов до 516 Мвыб. / с в каждом входном канале.

Области применения AD9171: инфраструктура беспроводных систем связи, передатчики однодиапазонных базовых станций, контрольно-измерительная техника, оборудование для автоматизированного тестирования.

Analog Devices представил также новинку в категории ЦАП с интерфейсом токовой петли 4-20 мА - AD5758 (рис. 9). Этот одноканальный 16-разрядный ЦАП с токовым выходом и выходом по напряжению работает от источника питания в диапазоне от -33 до 33 В с максимальным рабочим напряжением между шинами питания 60 B.

Встроенная схема динамического контроля мощности минимизирует рассеиваемую ЦАП мощность путем регулирования напряжения питания микросхемы с помощью вольтодобавочного (buck) DC/DC-преобразователя. Токовый выход AD5758 совместим с сигналами стандарта HART

В устройстве предусмотрен универсальный 4-проводный последовательный интерфейс, который работает на частоте до 50 МГц и совместим со стандартными интерфейсами SPI, QSPI, MICROWIRE и интерфейсами микроконтроллеров. Этот интерфейс также может быть 
опционально оснащен функцией контроля циклическим избыточным кодом и сторожевым таймером.

B AD5758 реализованы усовершенствованные функции диагностики, такие как мониторинг выходного тока и встроенный диагностический 12-разрядный АЦП. Дополнительную надежность ЦАП обеспечивает ключ защиты от короткого замыкания на выводах $\mathrm{VI}_{\text {OUT }},+\mathrm{V}_{\text {SENSE }}$ И $-\mathrm{V}_{\text {SENSE. }}$ Типовое время установления AD5758 составляет 15 мкс.

AD5758 поставляется в 32-выводных корпусах LFCSP $(5 \times 5$ мм $)$ и работает в диапазоне температур от -40 до $115^{\circ} \mathrm{C}$.

Основные области применения AD5758: системы управления технологическим процессом, управление приводами, промышленные программируемые логические контроллеры, распределенные системы управления, сети HART.

Новинка в категории прецизионных ЦАП - LTC2662 (рис. 10). Это семейство 5-канальных 16-разрядных ЦАП обеспечивает на выходе пять источников тока с гарантированным падением напряжения 1 В при токе 200 мА. Устройство поддерживает нагрузочные напряжения до 32 В. B LTC2662 предусмотрено восемь программируемых диапазонов выходного тока (от 3,125 до 300 мА). Выходные каналы можно включать параллельно для повышенной точной регулировки больших токов или для объединения каналов, чтобы обеспечить выходной ток до 1,5 А.

Для каждого выходного канала предусмотрен отдельный вывод источника питания, на который можно подавать напряжение от 2,85 до 33 В. Встроенные ключи позволяют подключать любой из выходов к опциональному источнику отрицательного напряжения.

B LTC2662 встроен прецизионный опорный источник напряжения 1,25 В (с максимальным дрейфом 10 ppm / ${ }^{\circ} \mathrm{C}$ ), возможно также подключение внешнего опорного источника. Последовательный 3-проводной SPI / MICROWIREсовместимый интерфейс работает на логических уровнях всего 1,71 В при частоте тактового сигнала до 50 Мгц.

LTC2662 поставляется в 32-выводном корпусе ( 5 × 5 мм) и работает в диапазоне температур от -40 до $125^{\circ} \mathrm{C}$. ЦАП применяется в таких областях, как перестраиваемые лазеры, полупроводниковые оптические усилители,

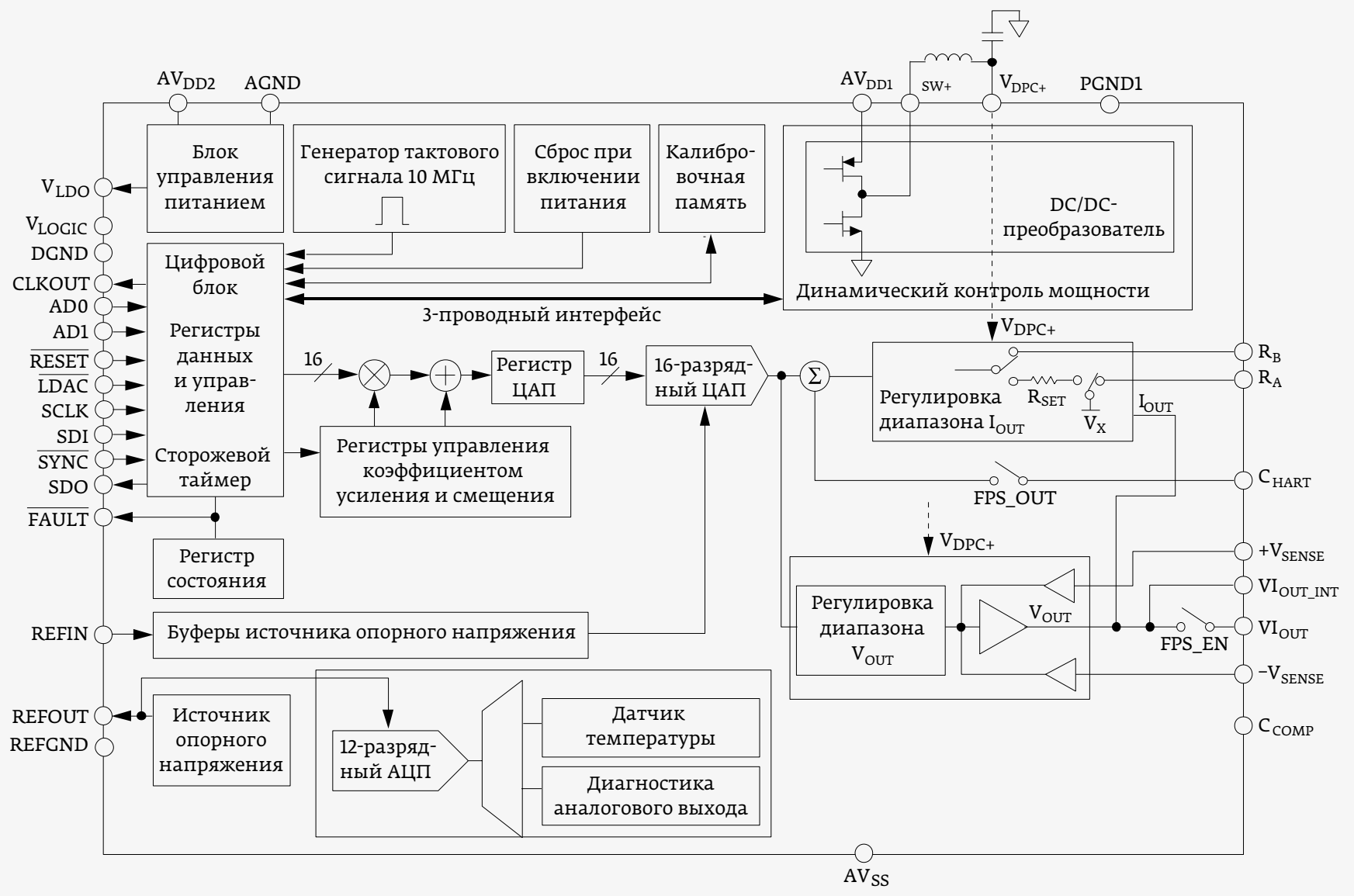

Рис. 9. Блок-схема ЦАП AD5758 


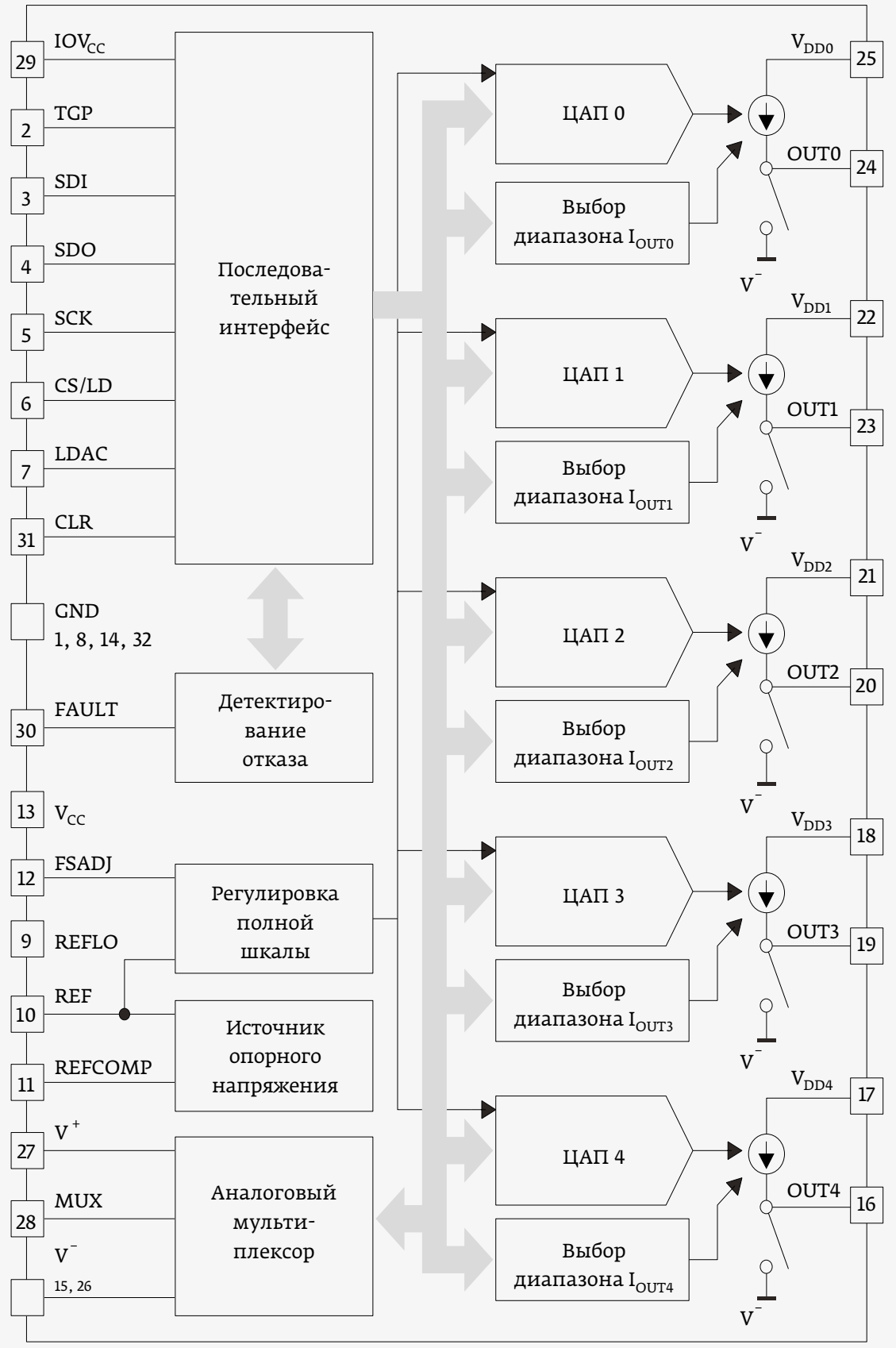

Рис. 10. Блок-схема ЦАП LТС2662

резистивные нагреватели, а также для построения токовых схем смещения.

\section{ОБЛАСТИ ПРИМЕНЕНИЯ В РОССИИ}

Продукция Analog Devices, в частности АЦП и ЦАП разных классов, хорошо известна в нашей стране, пользуется стабильным спросом среди разработчиков и производителей электронной техники различного назначения. Наиболее перспективные области применения в России высокоскоростных АЦП - радиолокационные системы, базовые станции сотовой связи, средства радиоэлектронной борьбы, радиосистемы связи гражданского и военного назначения. Кроме того, эта категория АЦП востребована для построения радиочастотных измерительных систем, систем неразрушающего контроля и высокоскоростных систем сбора данных.

Прецизионные АЦП находят применение в системах промышленной автоматизации (в программируемых логических контроллерах и распределенных системах управления) и высококачественных системах сбора данных.

АЦП с одновременной выборкой востребованы у российских разработчиков во многих промышленных приложениях, в частности системах автоматизации распределительной сети, управлении двигателями, системах промышленного управления, а также измерительных системах и многоканальных системах сбора данных.

Области применения быстродействующих ЦАП: инфраструктура беспроводных коммуникаций, многодиапазонные базовые станции связи поколения 4G / 5G, контрольно-измерительные системы, автоматизированное тестовое оборудование, радары и станции радиопомех. Кроме того, кперспективным в России областям применения ЦАП относятся системы управления технологическим процессом, управление электроприводом, промышленные программируемые логические контроллеры, распределенные системы управления. Прецизионные ЦАП незаменимы для построения высокоточных контрольно-измерительных систем .

Для получения более подробной технической информации по изделиям Analog Devices и заказа продукции/образцов обращайтесь в холдинг «золотой Шар» (www.zolshar.ru). 